\title{
ANÁLISE MECÂNICA-EMPIRICA DE UM PAVIMENTO FLEXÍVEL EM FUNÇÃO DO FENÔMENO DE FADIGA DE MISTURAS ASFÁLTICAS
}

\author{
MECHANICAL-EMPIRICAL ANALYSIS OF A FLEXIBLE PAVEMENT AS A FUNCTION OF THE \\ FATIGUE PHENOMENON OF ASPHALT MIXTURES
}

\section{Cássio Alberto Teoro do Carmo ${ }^{1}$, Geraldo Luciano de Oliveira Marques ${ }^{2}$, Géssica Soares Pereira ${ }^{3}$, Paulo Roberto Borges ${ }^{4}$}

${ }^{1}$ Universidade Federal de Viçosa (UFV), Huesker Ltda.. cassiocarmo@gmail.com.

${ }^{2}$ Universidade Federal de Juiz de Fora (UFJF). geraldo.marques@ufjf.edu.br

${ }^{3}$ Universidade Federal de Viçosa (UFV). gessicasoares.p@gmail.com

${ }^{4}$ Universidade Federal de São João Del Rei (UFSJ). paroborges@yahoo.com.br

Recebido:

17 de dezembro de 2020

Aceito para publicação:

08 de fevereiro de 2021

Publicado:

30 de março de 2021

Editor de área:

Antônio C. R. Guimarães

Palavras-chaves:

Misturas Asfálticas.

Ensaios Mecânicos de

Laboratório.

Análise Mecânica-

empírica.

Vida de Fadiga.

Keywords:

Asphaltic Mixtures.

Laboratory Mechanical

Testing.

Mechanistic-empirical

Analysis.

Fatigue Life

DOI:

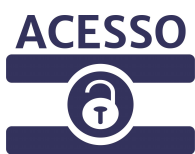

ABERTO

\section{RESUMO}

Esta pesquisa teve por objetivo avaliar a vida de fadiga de quatro misturas asfálticas à quente nos seus respectivos teores de projeto de ligante asfáltico, sendo duas enquadradas na faixa granulométrica $\mathrm{C}$ (capa asfáltica) e duas na faixa granulométrica $\mathrm{B}$ (binder) da especificação de serviço do DNIT para concretos betuminosos usinados a quente. O programa experimental desenvolvido combinou um ligante asfáltico (CAP 50/70), uma composição de agregados minerais de origem gnáissica, dois métodos de dosagem (Marshall e Superpave) e os ensaios de estabilidade e fluência Marshall, módulo de resiliência (MR), resistência à tração por compressão diametral (RT) e fadiga por compressão diametral à tensão controlada. Os parâmetros das misturas asfálticas resultantes foram aplicados na estrutura do pavimento flexível analisado pelo software Mechanistic Empirical Pavement Analysis and Design Software (me-PADS v1.1), visando a obtenção das respostas estruturais referentes às deformações na superfície desse pavimento e as tensões nas fibras inferiores das camadas asfálticas. Dos resultados obtidos, conclui-se que as misturas asfálticas dosadas pelo método Superpave apresentaram melhor desempenho em fadiga do que as misturas asfálticas dosadas pelo método Marshall, e que ao serem combinados os fatores: método de dosagem Superpave, adequados teores de projeto de ligante asfáltico e agregados de granulometria mais densa - obtêm-se misturas asfálticas com melhores resultados de vida em fadiga.

\section{ABSTRACT}

The objective of this research was to evaluate the fatigue life of four hot-mix asphalt in their respective asphalt binder design content, two being classified in the gradation range $\mathrm{C}$ (asphalt layer) and two in the gradation range B (binder) of the service specification of DNIT for hot-bituminous concretes. The experimental program developed combined an asphalt binder (CAP 50/70), a composition of mineral aggregates of gneiss formation, two dosing methods (Marshall and Superpave) and the Stability and Marshall Fluency, resilience modulus (MR), tensile strength testing by diametral compression (RT) and diametrical compression fatigue to the controlled tension. The parameters of the resulting asphalt mixtures were applied in the flexible pavement structure analyzed by the software Mechanistic Empirical Pavement Analysis and Design Software (me-PADS v1.1), aiming to obtain the structural responses concerning the deformations in the surface of that pavement and the tensions in the fibers asphaltic layers. From the results obtained, it was concluded that the asphalt mixtures dosed by the Superpave method presented better performance in fatigue than the asphalt mixtures dosed by the Marshall method, and that when the factors are combined: Superpave dosage method, suitable asphalt binder and denser aggregates better fatigue life results are obtained. 


\section{INTRODUÇ̃̃O}

No Brasil, o trincamento por fadiga é um dos principais problemas observados nos revestimentos asfálticos de pavimentos flexíveis. De acordo com Fritzen e Motta (2016), esse fenômeno tem uma natureza complexa e pode estar relacionado a vários fatores, tais como: (i) escolha dos materiais, (ii) efeitos climáticos, e (iii) características do tráfego e da estrutura do pavimento. Segundo Mashaan et al. (2014), o projeto de misturas asfálticas deve envolver a seleção e dosagem de materiais para se obter as propriedades desejadas, fornecendo uma resposta estrutural condizente com as solicitações do tráfego e climáticas.

As solicitações do tráfego englobam: (i) magnitude do carregamento; (ii) tipo de carregamento; (iii) frequência, duração e intervalo de tempo entre aplicações sucessivas do carregamento; (iv) tipos de tensões e (v) forma do carregamento (AL-QADI; NASSAR, 2003). Já as solicitações climáticas referem-se a: (i) temperatura; e (ii) umidade. Segundo Modarres e Hamedi (2014), as trincas por fadiga ocorrem principalmente em temperaturas médias e baixas, pois a redução da temperatura aumenta a rigidez do ligante asfáltico e, nessas temperaturas, a mistura asfáltica tende a se comportar como um material frágil. No Brasil, os procedimentos de ensaio de fadiga propõem analisar as respostas à fadiga da mistura asfáltica a temperatura de 25oC (ME-135, DNIT, 2018).

Segundo Moghadas Nejad, Aflaki e Mohammadi (2010), o aumento da temperatura no ensaio de fadiga por tração indireta diminuirá o módulo de rigidez e consequentemente a vida de fadiga da mistura asfáltica. Estes autores afirmam que essa tendência é independente da granulometria do agregado e do teor de asfalto que compõem a mistura asfáltica. Moghaddam, Karim e Abdelaziz (2011) observaram que misturas asfálticas com granulometria aberta e maior teor de ligante asfáltico apresentaram menor vida de fadiga, embora a granulometria aberta seja um ponto positivo para o desempenho quanto à deformação permanente de misturas asfálticas a quente. Por outro lado, misturas asfálticas de granulometrias densas têm melhor desempenho em fadiga, sendo que o efeito da granulometria na vida de fadiga é mais importante do que o teor de ligante da mistura asfáltica (MOGHADAS NEJAD; AFLAKI; MOHAMMADI, 2010).

Outro fator que também afeta o desempenho das misturas asfálticas é o processo de compactação. $\mathrm{Wu}$, Liu e Sun (2018) destacam que os equipamentos utilizados para a dosagem de misturas asfálticas pelo método Marshall são mais baratos que os utilizados para a dosagem pelo método Superpave. Estudos mostram que a compactação por impacto (Marshall) não é realista em comparação com a compactação giratória do procedimento Superpave, que simula de forma mais adequada as condições de compactação no campo (PÉREZ-JIMÉNEZ et al., 2014; AL-MISTAREHI, 2014).

Braz; Lopes; Motta (2004), utilizaram a tomografia para analisar ensaios de fadiga de misturas asfálticas, indicando que o caminhamento de trincas se ramifica dependendo da granulometria dos agregados, entre outros fatores.

Nascimento; Leite; Marques e Motta (2007) avaliaram por tomografia corpos de prova de misturas asfálticas preparadas com o compactador Mashall e com o giratório, bem como retirados de pistas. Mostram que a estrutura do esqueleto mineral obtida na compactação giratória se aproxima muito mais da obtida pela compactação em campo do que a da compactação Marshall.

Pesquisas realizadas por Karimi, Goulias e Schwartz (2012), Jitsangiam, Chindaprasirt e Nikraz (2013), Han, Wei e Zhang (2016) indicam que o método de dosagem Superpave produz misturas asfálticas com menores teores de ligante asfáltico em relação àquelas dosadas pelo método Marshall, porém essas últimas atingiram mais dificilmente a densidade de projeto na compactação em campo, o que pode gerar problemas de durabilidade, como o trincamento prematuro. 
Para Melo e Trichês (2016), o ligante asfáltico e o agregado exercem papel fundamental no comportamento mecânico de misturas asfálticas: o ligante asfáltico, como resultado de sua consistência e reologia e o agregado em decorrência das forças de atrito internas entre suas partículas.

Vasconcelos (2004) realizou ensaios para a determinação da vida de fadiga de misturas asfálticas com diferente granulometrias e métodos de dosagem, nos quais se verificou uma tendência de maior vida de fadiga das misturas asfálticas dosadas pelo método Superpave com relação às misturas asfálticas dosadas pelo método Marshall, atribuindo este fato a distribuição granulométrica dos agregados e também ao processo de envelhecimento de curto prazo. Observou-se, ainda, que os teores de projeto de ligante asfáltico das misturas dosadas pelo método Superpave foram maiores que os das misturas asfálticas dosadas pelo método Mashall. A autora investigou os parâmetros que influenciaram estes resultados, atribuindo o aumento no teor de projeto de ligante asfáltico à forma como a Densidade Máxima Teórica (DMT) foi determinada, através da ponderação das densidades reais dos materiais constituintes (sendo influenciadas, principalmente, pela granulometria da mistura, quando comparadas misturas contínuas e descontínuas), bem como ao processo de compactação empregado.

De acordo com Pinto (1991), os ensaios de fadiga por compressão diametral em amostras asfálticas são realizados sob deformação controlada (DC) ou tensão controlada (TC). No ensaio à deformação controlada, o critério de fadiga não está condicionado à ruptura completa do corpo de prova, mas ao número de solicitações capaz de reduzir a carga necessária em 40 a $50 \%$ da carga inicial para manter a deformação constante ou reduzir a rigidez inicial da amostra a um valor determinado previamente. No ensaio de fadiga com tensão controlada (TC), o critério de fadiga está associado à ruptura do corpo de prova, onde a carga aplicada é mantida constante e as deformações aumentam no decorrer do ensaio. Arabani e Mirabdolazimi (2011), Alatas et al. (2012) e Mashaan et al. (2014) ressaltaram a simplicidade e eficiência do ensaio de fadiga baseado no método de compressão diametral com tensão controlada.

$\mathrm{O}$ módulo de resiliência $(\mathrm{MR})$ da mistura asfáltica está relacionado à rigidez da estrutura. As misturas asfálticas com módulos de resiliência elevados induzem a altos valores de resistência à tração (RT), devido à concentração de esforços no interior da mistura asfáltica. Segundo Bock et al. (2009) e Mendes e Marques (2012), a relação entre MR e RT indica a compatibilidade entre a rigidez e a resistência à tração da mistura asfáltica. Alguns pesquisadores acreditam que menores valores da relação MR/RT resultem em misturas com maior vida de fadiga. Leite et al. (2000) e Pinheiro, Soares e Leite (2003) sugerem que misturas asfálticas com relação MR/RT da ordem de 3000 apresentam um bom comportamento estrutural, em razão da flexibilidade aliada à resistência à tração e, portanto, maior vida de fadiga.

Diante do exposto, o objetivo dessa pesquisa foi avaliar a vida de fadiga de quatro misturas asfálticas a quente nos seus respectivos teores de projeto de ligante asfáltico, sendo duas enquadradas na faixa granulométrica $\mathrm{C}$ e duas na faixa granulométrica $\mathrm{B}$ da especificação de serviço ES-031 (DNIT, 2006). Para tanto, foram realizados ensaios de módulo de resiliência, resistência à tração por compressão diametral e fadiga por compressão diametral com tensão controlada (TC) em corpos de prova das quatro misturas asfálticas dosadas segundo os métodos Marshall e Superpave. A análise mecanística-empírica de um pavimento flexível adotado, sob condições específicas de carregamento, foi realizada através do software me-PADS (Mechanistic Empirical Pavement Analysis and Design Software). 


\section{Revista PAVIMENTAÇÃO}

\section{MATERIAIS E MÉTODOS}

\subsection{Materiais}

Nesta pesquisa utilizaram-se os agregados minerais (brita 1, brita 0 e pó de pedra), de formação gnáissica de jazida localizada na Microrregião de Viçosa, Estado de Minas Gerais, Brasil.

O cimento asfáltico de petróleo convencional (CAP 50/70) foi fornecido por uma empresa privada e oriundo da Refinaria Gabriel Passos (REGAP), localizada no Município de Betim, Estado de Minas Gerais, Brasil.

\subsection{Métodos}

\subsubsection{Análise granulométrica dos agregados minerais}

As análises granulométricas dos agregados minerais graúdos e miúdos foram determinadas conforme o método de ensaio ME-083 (DNER, 1998), e se enquadraram na especificação de serviço ES-031 (DNIT, 2006) para as misturas asfálticas dosadas pelo método Marshall, enquanto que para as misturas asfálticas dosadas pelo método Superpave foram adotadas as seguintes normas técnicas: AS-95-003 (FHWA, 1994), A-407 (SHRP, 1994) e R 35 (AASHTO, 2014).

$\mathrm{Na}$ Figura 1, têm-se as curvas granulométricas da faixa de serviço C, para as misturas asfálticas $1 \mathrm{e}$ 3, e na Figura 2 são apresentadas as curvas granulométricas da faixa de serviço B, para as misturas asfálticas 2 e 4.

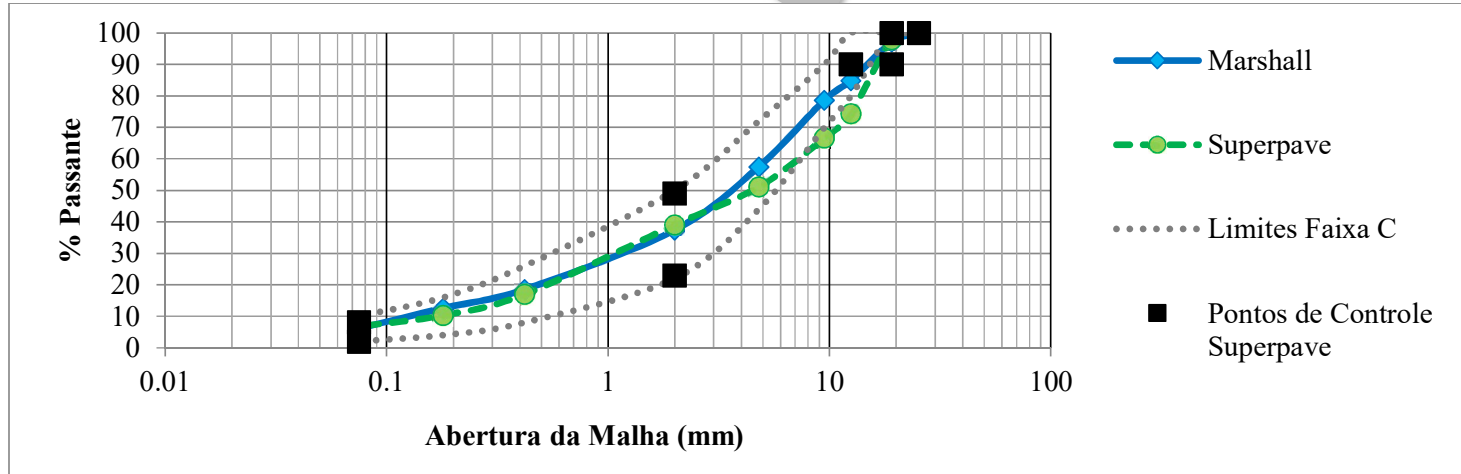

Figura 1: Curvas granulométricas estudadas para a faixa granulométrica $\mathrm{C}$ para as misturas asfálticas 1 e 3 .

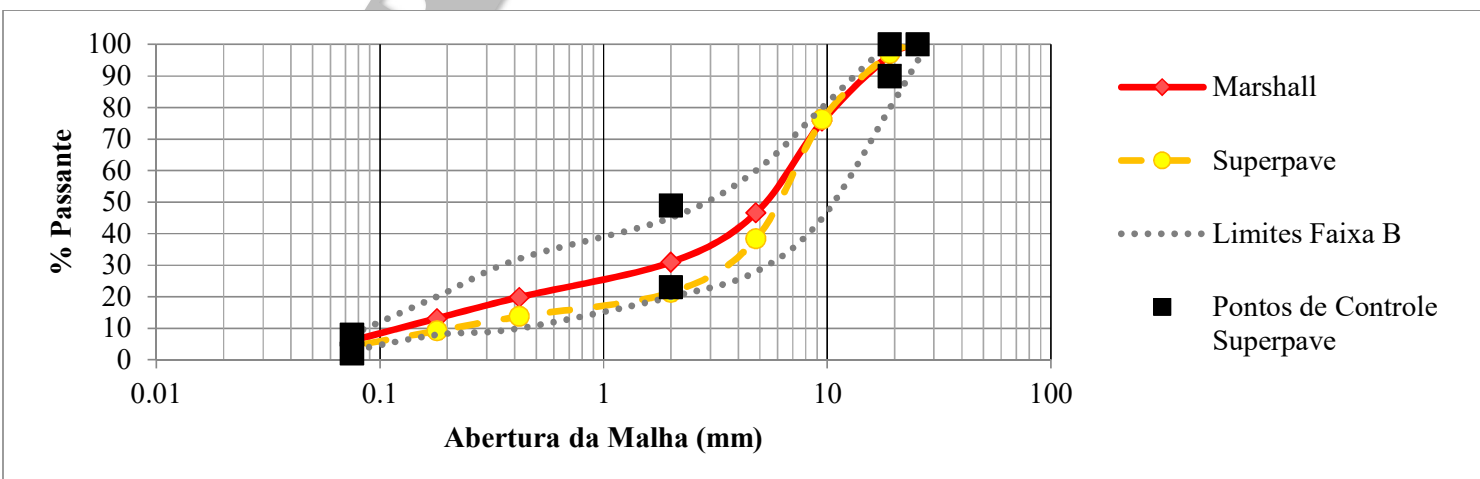

Figura 2: Curvas granulométricas estudadas para a faixa granulométrica C para as misturas asfálticas 2 e 4. 


\section{Revista}

\subsubsection{Dosagem de misturas asfálticas}

Nesta pesquisa utilizaram-se quatro composições granulométricas contínuas para as misturas asfálticas densas de projeto, sendo duas enquadradas na faixa granulométrica $\mathrm{C}$ e duas na faixa granulométrica $\mathrm{B}$, da especificação de serviço ES-031 (DNIT, 2006). As misturas asfálticas das composições granulométricas 1 e 2 foram dosadas pelo método Marshall, conforme o método de ensaio D6926 (ASTM, 2016), e inseremse nas faixas granulométricas $\mathrm{C}$ e $\mathrm{B}$, respectivamente. As composições granulométricas das misturas asfálticas 3 e 4 foram dosadas pelo método Superpave (Nível 1), com envelhecimento de 2 horas, conforme as recomendações AS-95-003 (FHWA, 1994), A-407 (SHRP, 1994) e R 35 (AASHTO, 2014), e, também, estão inseridas nas faixas granulométricas $\mathrm{C}$ e B, respectivamente, de modo que as composições granulometrias atendem ao critério estabelecido nas normas técnicas supracitadas quanto ao tamanho nominal máximo (TNM) de 19,0mm.

\subsubsection{Moldagem dos corpos de prova}

Os corpos de prova das misturas asfálticas dosadas pelo método Marshall foram moldados segundo o procedimento de ensaio D6926 (ASTM, 2016), utilizando-se 75 golpes por face no compactador Marshall, já para atendimento ao método de dosagem Superpave, os corpos de prova foram moldados conforme o procedimento de ensaio R 35 (AASHTO, 2014), aplicando-se 100 giros no compactador giratório Superpave.

\subsubsection{Propriedades mecânicas dos corpos de prova}

\subsubsection{Estabilidade e fluência Marshall}

Foram realizados ensaios de laboratório para a determinação das propriedades mecânicas Estabilidade e Fluência Marshall de corpos de provas de misturas asfálticas dosadas pelos métodos Marshall e Superpave, conforme recomendações do método de ensaio D6927 (ASTM, 2015).

\subsubsection{Módulo de resiliência}

Foram realizados ensaios de laboratório para a determinação dos módulos de resiliência de corpos de prova das misturas asfálticas dosadas pelos métodos Marshall e Superpave, conforme recomendações do método de ensaio ME 135 (DNIT, 2018) e D7369 (ASTM, 2011).

\subsubsection{Ensaio de resistência à tração por compressão diametral}

Foram realizados ensaios de resistência à tração por compressão diametral (RT) em corpos de provas das misturas asfálticas analisadas e dosadas pelos métodos Marshall e Superpave de acordo com os métodos de ensaio ME 136 (DNIT, 2018) e D6931 (ASTM, 2017), sendo as rupturas desses corpos de prova feitas à velocidade recomendada no ensaio Marshall $(0,83 \mathrm{~mm} / \mathrm{s})$.

\subsubsection{Ensaio de fadiga por compressão diametral}

Foram realizados ensaios de laboratório para a determinação de valores de fadiga por compressão diametral com tensão controlada de corpos de prova das misturas asfálticas dosadas pelo método Marshall e Superpave, aplicando-se carregamentos de 15\%, 20\%, 25\%, 30\%, 35\% e 40\% da tensão de ruptura do corpo de prova obtido no ensaio de resistência à tração por compressão diametral (RT), e em conformidade com o método de ensaio ME 183 (DNIT, 2018). 


\section{RESULTADOS E DISCUSSÕES}

\subsection{Parâmetros volumétricos das dosagens Marshall e Superpave}

$\mathrm{Na}$ Tabela 1 são apresentados os parâmetros volumétricos das misturas asfálticas analisadas em seus respectivos teores de projeto de ligante asfáltico, além das propriedades mecânicas de estabilidade e fluência Marshall.

Observa-se que o teor de projeto de ligante asfáltico da mistura asfáltica da faixa granulométrica $\mathrm{C}$ obtido pela dosagem Marshall é maior do que o obtido pela dosagem Superpave. Já para as misturas asfálticas que se enquadraram na faixa granulométrica $\mathrm{B}$, o teor de ligante asfáltico dosado pelo método Superpave foi maior do que o obtido pelo método Marshall (4,2\% na dosagem Marshall e 4,85\% na dosagem Superpave), corroborando os achados de Vasconcelos (2004) que também obteve maiores valores de teores de projeto para as misturas dosadas pelo método Superpave.

É consenso na literatura técnica que o método de dosagem e a energia de compactação influenciam o teor de projeto da mistura asfáltica. Neste estudo, esta assertiva também foi constatada. Porém, os resultados dos ensaios de caracterização volumétrica evidenciaram também que a distribuição granulométrica dos agregados influencia os valores de teor de projeto de ligante asfáltico, consoante com os resultados obtidos por Vasconcelos (2004) quando esta autora afirma que a forma como é determinada a DMT interfere no aumento do teor de projeto, principalmente quando são comparadas misturas contínuas e descontínuas.

Tabela 1: Parâmetros volumétricos e propriedades mecânicas de corpos de prova moldados das misturas asfálticas analisadas.

\begin{tabular}{|c|c|c|c|c|c|}
\hline Parâmetros & $\begin{array}{c}\text { Valores de } \\
\text { referência - ES-031 } \\
\text { (DNIT, 2006b) }\end{array}$ & $\begin{array}{c}\text { Mistura } \\
\text { asfáltica } 1 \\
\end{array}$ & $\begin{array}{c}\text { Mistura } \\
\text { asfáltica } 2\end{array}$ & $\begin{array}{c}\text { Mistura } \\
\text { asfáltica } 3\end{array}$ & $\begin{array}{c}\text { Mistura } \\
\text { asfáltica } 4\end{array}$ \\
\hline Método de dosagem & - & \multicolumn{2}{|c|}{ Marshall } & \multicolumn{2}{|c|}{ Superpave } \\
\hline $\begin{array}{l}\text { Envelhecimento de } \\
\text { Curto Prazo }\end{array}$ & - & \multicolumn{2}{|c|}{ NA } & \multicolumn{2}{|c|}{2 horas } \\
\hline Faixa granulométrica & $\mathrm{B}$ & $\mathrm{C}$ & $\mathrm{B}$ & $\mathrm{C}$ & $\mathrm{B}$ \\
\hline $\begin{array}{l}\text { Diâmetro Nominal } \\
\text { Máximo do Agregado }\end{array}$ & & $12,5 \mathrm{~mm}$ & $25,4 \mathrm{~mm}$ & $12,5 \mathrm{~mm}$ & $25,4 \mathrm{~mm}$ \\
\hline $\begin{array}{c}\text { Teor de projeto de } \\
\text { ligante asfáltico }(\%)\end{array}$ & & 4,70 & 4,20 & 4,60 & 4,85 \\
\hline Vv (\%) & $4 \mathrm{a} 6$ & 4,19 & 4,49 & 4,28 & 4,75 \\
\hline RBV (\%) & \begin{tabular}{l|l}
75 a 82 & 65 a 72 \\
\end{tabular} & 75,99 & 70,39 & 75,14 & 71,43 \\
\hline VAM (\%) & $-1-$ & 15,23 & 14,71 & 15,55 & 16,48 \\
\hline Estabilidade (kgf) & $>500$ & 524,45 & 535,34 & 867,68 & 854,93 \\
\hline Fluência (mm) & - & 3,50 & 1,20 & 4,81 & 4,70 \\
\hline $\begin{array}{l}\text { Massa específica } \\
\text { aparente }\left(\mathrm{g} / \mathrm{cm}^{3}\right)\end{array}$ & - & 2,478 & 2,480 & 2,473 & 2,458 \\
\hline $\operatorname{DMT}\left(\mathrm{g} / \mathrm{cm}^{3}\right)$ & - & 2,572 & 2,593 & - & - \\
\hline $\mathrm{Gmm}\left(\mathrm{g} / \mathrm{cm}^{3}\right)$ & - & - & - & 2,588 & 2,569 \\
\hline
\end{tabular}

*Em que: NA: Não Aplicável; Vv: volume de vazios; RBV: Relação Betume Vazios; VAM: Vazios do Agregado

Mineral; DMT: Densidade Máxima Teórica; Gmm: Densidade Máxima Medida da Mistura

Através da análise dos valores dos parâmetros de estabilidade e fluência Marshall apresentados na Tabela 1 percebeu-se uma indicação subjetiva da rigidez da mistura asfáltica. Verificou-se que as misturas 
asfálticas compactadas por amassamento apresentaram maiores valores de fluência e estabilidade Marshall, fato também observado por Gouveia, Fernandes JR e Soares (2007), que afirmam que a estabilidade Marshall varia conforme a energia de compactação aplicada, ou seja, maiores energias de compactação foram responsáveis por maiores valores desses parâmetros.

\subsection{Ensaio de Módulos de Resiliência e Resistências à Tração por Compressão Diametral.}

$\mathrm{Na}$ Tabela 2, são apresentados os valores médios dos módulos de resiliência (MR) e resistência à tração por compressão diametral (RT) obtidos dos corpos de prova das misturas asfálticas analisadas em função dos teores de projeto de ligante asfáltico, e as respectivas relações MR/RT.

Observa-se na Tabela 2 que, a despeito do fato de as composições asfálticas 1 e 3 apresentarem distribuições granulométricas semelhantes entre si (faixa granulométrica $\mathrm{C}$ ) e as composições asfálticas 2 e 4 também apresentarem distribuições granulométricas semelhantes entre si (faixa granulométrica B), as misturas asfálticas dosadas pelo método Superpave (composições asfálticas 3 e 4) apresentaram maiores valores de módulo de resiliência, evidenciando que, para as particularidades desta pesquisa, os corpos de prova resultantes da dosagem e compactação Superpave foram mais rígidos do que os corpos de prova dosados pelo método Marshall, para todos os valores do teor de projeto de ligante asfáltico, este fato poder estar relacionado com o processo de compactação e o período de envelhecimento que é recomendado no método Superpave.

Tabela 2: Valores médios de módulo de resiliência e resistência à tração por compressão diametral e a relação MR/RT para os corpos de prova das misturas asfálticas analisadas.

\begin{tabular}{|c|c|c|c|c|}
\hline Parâmetro & $\begin{array}{c}\text { Mistura } \\
\text { asfáltica 1 }\end{array}$ & $\begin{array}{c}\text { Mistura } \\
\text { asfáltica } 2 \\
\end{array}$ & $\begin{array}{c}\text { Mistura } \\
\text { asfáltica } 3\end{array}$ & $\begin{array}{c}\text { Mistura } \\
\text { asfáltica } 4 \\
\end{array}$ \\
\hline Método de dosagem & \multicolumn{2}{|c|}{ Marshall } & \multicolumn{2}{|c|}{ Superpave } \\
\hline Envelhecimento de Curto Prazo & \multicolumn{2}{|c|}{ NA } & \multicolumn{2}{|c|}{2 horas } \\
\hline Faixa granulométrica & $\mathrm{C}$ & $\mathrm{B}$ & $\mathrm{C}$ & B \\
\hline $\begin{array}{c}\text { Diâmetro Nominal Máximo do } \\
\text { Agregado }\end{array}$ & $12,5 \mathrm{~mm}$ & $25,4 \mathrm{~mm}$ & $12,5 \mathrm{~mm}$ & $25,4 \mathrm{~mm}$ \\
\hline Teor de projeto de ligante asfáltico & 4,70 & 4,20 & 4,60 & 4,85 \\
\hline Módulo de resiliência, MR (MPa) & 4073 & 3947 & 6673 & 5340 \\
\hline Resistência à tração, RT (MPa) & 1,49 & 1,33 & 1,92 & 1,42 \\
\hline Relação MR / RT & 2734 & 2968 & 3479 & 3760 \\
\hline
\end{tabular}

Portanto, os valores de módulo de resiliência (MR) das misturas asfálticas avaliadas foram predominantemente influenciados pelo método de dosagem, mesmo considerando-se distribuições granulométricas semelhantes, isto porque o método de dosagem Superpave considera o envelhecimento de curto prazo de 2 horas em seu método, o que não ocorre com o método Marshall. Os resultados médios de MR dos corpos de prova moldados pelo compactador giratório Superpave superiores $(63,8 \%$ na faixa granulométrica C e 35,3\% na faixa granulométrica B) em relação aos resultados obtidos para os corpos de prova moldados pelo compactador Marshall.

Com relação aos valores de resistência à tração por compressão diametral (RT) das misturas asfálticas analisadas, estas também foram influenciadas fortemente pelo método de dosagem, mesmo considerandose distribuições granulométricas semelhantes. Os valores médios de RT dos corpos de prova moldados pelo compactador giratório Superpave superiores (29\% na faixa granulométrica C e $7 \%$ na faixa granulométrica 


\section{Revista PAVIMENTAÇÃO}

B) em relação aos resultados obtidos para os corpos de prova moldados pelo compactador Marshall. Assim, os valores médios de MR/RT dos corpos de prova moldados pelo compactador Superpave resultam $27 \%$ superiores (em ambas as faixas granulométricas C e B) em relação aos resultados obtidos para os corpos de prova moldados pelo compactador Marshall.

Como indica a compatibilidade entre rigidez e resistência à tração da mistura asfáltica, esta relação vem sendo usada como um indicador de vida de fadiga, sendo mais desejável um valor pequeno da razão (MR/RT), já que, com frequência, busca-se, baixa rigidez para evitar elevada absorção de tensões que levem ao trincamento prematuro do revestimento, e alta resistência à tração que é associada a uma maior resistência à fadiga.

\subsection{Ensaios de Fadiga por Compressão Diametral à Tensão Controlada}

$\mathrm{Na}$ Figura 3 são apresentados os resultados das curvas de fadiga, expressos em número de repetições versus diferença de tensões, para as misturas asfálticas dosadas pelos métodos Marshall e Superpave.

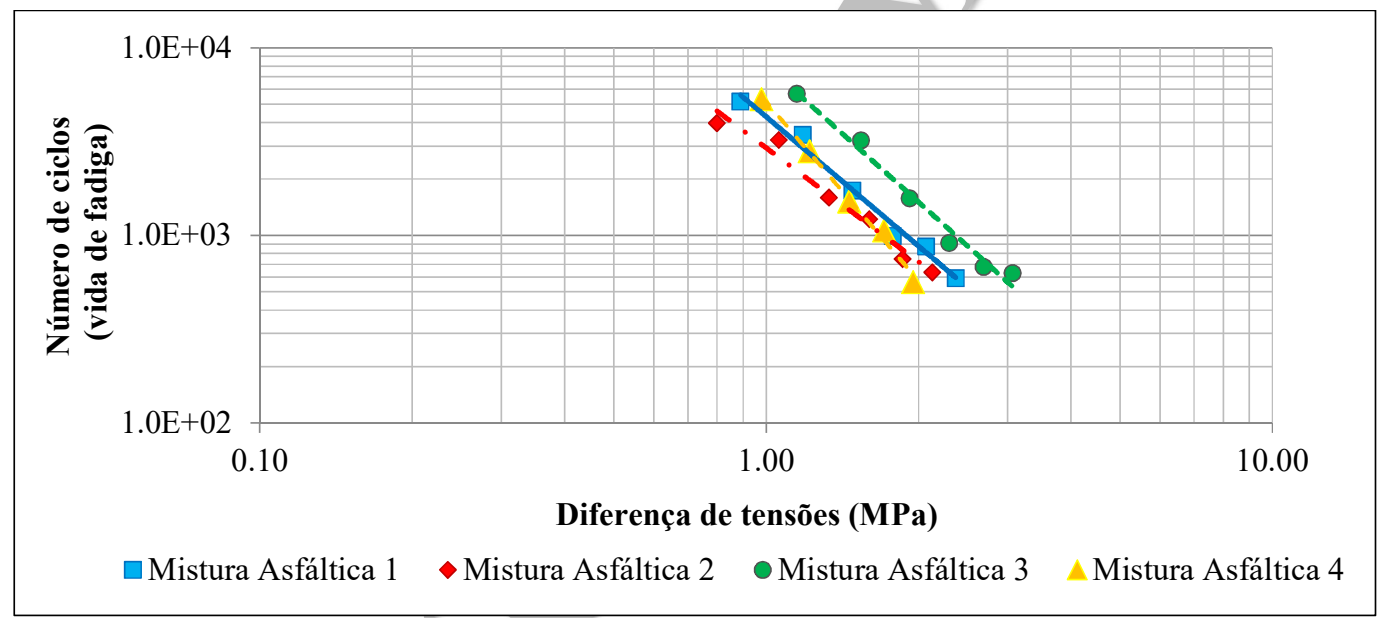

Figura 3: Curva de fadiga das misturas asfálticas analisadas em função da diferença de tensões $(\Delta \sigma)$.

$\mathrm{Na}$ Tabela 3, estão apresentadas as constantes " $\mathrm{k}_{1}$ e k2" obtidas na regressão linear das curvas de fadiga para o modelo apresentado na Equação 1 referentes às misturas asfálticas analisadas.

$$
\begin{aligned}
& V F=k_{1} * \Delta \sigma^{k_{2}} \\
& \Delta \sigma=\sigma_{x}-\sigma_{z}
\end{aligned}
$$

Em que:

VF: número de ciclos de vida em fadiga;

$\Delta \sigma$ : diferença de tensões (MPa);

$\sigma_{\mathrm{x}}: \sigma_{\mathrm{h}}:$ tensão horizontal;

$\sigma_{\mathrm{z}}: \sigma_{\mathrm{v}}:$ tensão vertical;

$\mathrm{k}_{1}$ e $\mathrm{k}_{2}$ : constantes obtidas na regressão linear. 
Tabela 3: Parâmetros das curvas de fadiga das misturas asfálticas analisadas.

\begin{tabular}{|c|c|c|c|c|c|}
\hline \multicolumn{2}{|c|}{ Parâmetro } & $\begin{array}{c}\text { Mistura } \\
\text { asfáltica } 1\end{array}$ & $\begin{array}{c}\text { Mistura } \\
\text { asfáltica } 2\end{array}$ & $\begin{array}{c}\text { Mistura } \\
\text { asfáltica } 3\end{array}$ & $\begin{array}{c}\text { Mistura } \\
\text { asfáltica } 4\end{array}$ \\
\hline \multicolumn{2}{|c|}{ Método de dosagem } & \multicolumn{2}{|c|}{ Marshall } & \multicolumn{2}{|c|}{ Superpave } \\
\hline \multicolumn{2}{|c|}{ Envelhecimento de Curto Prazo } & \multicolumn{2}{|c|}{ NA } & \multicolumn{2}{|c|}{2 horas } \\
\hline \multicolumn{2}{|c|}{ Faixa granulométrica } & $\mathrm{C}$ & $\mathrm{B}$ & $\mathrm{C}$ & $\mathrm{B}$ \\
\hline \multicolumn{2}{|c|}{$\begin{array}{l}\text { Diâmetro Nominal Máximo do } \\
\text { Agregado }\end{array}$} & $12,5 \mathrm{~mm}$ & $25,4 \mathrm{~mm}$ & $12,5 \mathrm{~mm}$ & $25,4 \mathrm{~mm}$ \\
\hline \multicolumn{2}{|c|}{$\begin{array}{c}\text { Teor de projeto de ligante asfáltico } \\
(\%)\end{array}$} & 4,70 & 4,20 & & 4,85 \\
\hline \multirow{2}{*}{$\begin{array}{l}\text { Constante da } \\
\text { regressão linear }\end{array}$} & $\mathrm{K}_{1}$ & 4292,9 & 2930,0 & 8068,1 & 5153,7 \\
\hline & $\mathrm{K}_{2}$ & $-2,289$ & $-2,017$ & 22 & $-3,168$ \\
\hline \multicolumn{2}{|c|}{$\mathrm{R}^{2}$} & 0,984 & 0,969 & 0,980 & 0,992 \\
\hline
\end{tabular}

Observa-se que todas as curvas apresentaram boa correlação linear com $\mathrm{R}^{2}$ acima de 0,96 . As curvas correspondentes às composições asfálticas 3 e 4 (dosadas pelo método Superpave) apresentaram maiores inclinações do que aquelas correspondentes às misturas asfálticas dosadas pelo método Marshall (composições asfálticas 1 e 2), sendo que a mistura asfáltica 4 apresentou inclinação da curva de fadiga, $57 \%$ acima da curva correspondente à mistura asfáltica 2 (ambas pertencentes à faixa granulométrica $\mathrm{B}$ ). Isto levou a menores valores de vida de fadiga (VF) quando os corpos de prova da mistura asfáltica 4 foram submetidos a valores de diferenças de tensões $(\Delta \sigma)$ maiores.

Analisando-se os resultados do ensaio de vida de fadiga através da variação de diferença de tensões $(\Delta \sigma)$, percebe-se que as misturas asfálticas dosadas pelo método Superpave (composições asfálticas 3 e 4 ) apresentaram melhores resultados em relação às misturas dosadas pelo método Marshall (consoante com os resultados de VASCONCELOS, 2004). Considerando o valor da diferença de tensões $(\Delta \sigma)$ da ordem de $1,0 \mathrm{MPa}$ as misturas asfálticas 3 e 4 (faixas granulométricas $\mathrm{C}$ e $\mathrm{B}$, respectivamente), dosadas pelo método Superpave, apresentaram maiores valores de vida de fadiga (VF), $\mathrm{VF}=7 \times 10^{3}$, e VF= $5 \times 10^{3}$, respectivamente. Enquanto as misturas asfálticas 1 e 2 (faixas granulométricas $\mathrm{C}$ e $\mathrm{B}$, respectivamente), dosadas pelo método Marshall, apresentaram os menores valores de vida de fadiga (VF), $\mathrm{VF}=4 \times 10^{3}$ e $\mathrm{VF}=3 \times 10^{3}$, respectivamente, para este valor de $\Delta \sigma$. Estes resultados indicam que, para valores baixos de $\Delta \sigma$, o método de dosagem apresenta influência predominante sobre a vida de fadiga (VF) e que a granulometria do agregado também afeta os valores de VF; sendo os maiores valores de VF obtidos para as misturas asfálticas com granulometrias densas dosadas pelo método Superpave.

No entanto, para valores mais altos de $\Delta \sigma(2,0 \mathrm{MPa})$, as misturas asfálticas 3 e 4 , dosadas pelo método Superpave, obtiveram o menor e o maior valor de vida de fadiga, em que a mistura asfáltica 4 (faixa granulométrica B) apresentou $\mathrm{VF}=5 \times 10^{2}$ e a mistura asfáltica 3 (faixa granulométrica $\mathrm{C}$ ) $\mathrm{VF}=1,7 \times 10^{3}$. As misturas asfálticas dosadas pelo método Marshall apresentaram valores de vida de fadiga intermediários, obtendo-se para a mistura asfáltica 1 (faixa granulométrica $\mathrm{C}$ ) $\mathrm{VF}=9 \times 10^{2}$, e para a mistura asfáltica 2 (faixa granulométrica $\mathrm{B}), \mathrm{VF}=6 \times 10^{2}$. Donde se verifica que os valores de vida de fadiga (VF) para diferenças de tensões $(\Delta \sigma)$ maiores são predominantemente afetados pela distribuição granulométrica das misturas asfálticas e principalmente do método de dosagem empregado, sendo as granulometrias mais densas (faixa granulométrica $\mathrm{C}$ ) as que atingem maiores valores de $\mathrm{VF}$ em níveis de $\Delta \sigma$ mais altos, uma vez que estas misturas asfálticas apresentam maior rigidez se comparada com as misturas asfálticas da faixa Granulométrica B. 


\section{Revista}

Os modelos de fadiga encontrados nesta pesquisa necessitam ser calibrados de forma a corrigir os valores determinados em laboratório, e portanto, com condições específicas, tais como, carregamento e frequência de carregamento constantes, temperatura fixa, forma e tipo de compactação para os valores esperados no campo (FRANCO, 2000). A forma usual é a aplicação do fator campo laboratório (FCL).

Considerando-se a relação MR/RT, as misturas asfálticas dosadas pelo método Marshall apresentaram valores para esta relação mais próximos do sugerido por Pinheiro, Soares e Leite (2003). Apesar disso, os valores de vida de fadiga (VF) obtidos nos ensaios de fadiga por compressão diametral à tensão controlada com os corpos de prova destas misturas asfálticas não se mostraram superiores aos obtidos com os corpos de prova para as misturas asfálticas dosadas pelo método Superpave, cujos valores da relação MR/RT foram superiores em aproximadamente $27 \%$ aos valores encontrados para os corpos de provas das misturas asfálticas dosadas pelo método Marshall.

Estudos indicam que o método de compactação influencia a vida de fadiga das misturas asfálticas. Nesta pesquisa, os corpos de prova ensaiados foram compactados de acordo com as recomendações: da norma R 35 (AASHTO, 2014) para o método Superpave - considerando o nível de tráfego de projeto adotado (correspondente a vias principais, de tráfego médio a alto), com 100 giros do compactador Superpave para as misturas asfálticas 3 e 4; da especificação D6926 (ASTM, 2016) para o método Marshall - com 75 golpes do compactador por impacto para as misturas 1 e 2, para todos os níveis de tráfego.

Com isso, verifica-se que o método Superpave apresentou melhores resultados de vida de fadiga para as misturas asfálticas com granulometrias mais densas (VASCONCELOS, 2004), o que indica que granulometrias mais grossas exigem maior energia de compactação para promover o rearranjo das partículas dos agregados. Na mistura asfáltica 3, em que há uma combinação do método de compactação por amassamento com a granulometria mais densa da mistura asfáltica - que proporciona o aumento das forças de atrito interno entre as partículas dos agregados (MELO e TRICHÊS, 2016) - obteve-se maior valor de vida de fadiga (VF).

\section{ANÁLISE ESTRUTURAL DO PAVIMENTO FLEXÍVEL ADOTADO}

A Figura 4 apresenta um esquema do pavimento flexível adotado para a análise das tensões e deformações em alguns pontos de suas camadas e o carregamento com duas rodas aplicado na sua superfície. As características dos materiais utilizados nas camadas do subleito, reforço do subleito e base foram extraídas do estudo de Carmo (2019).

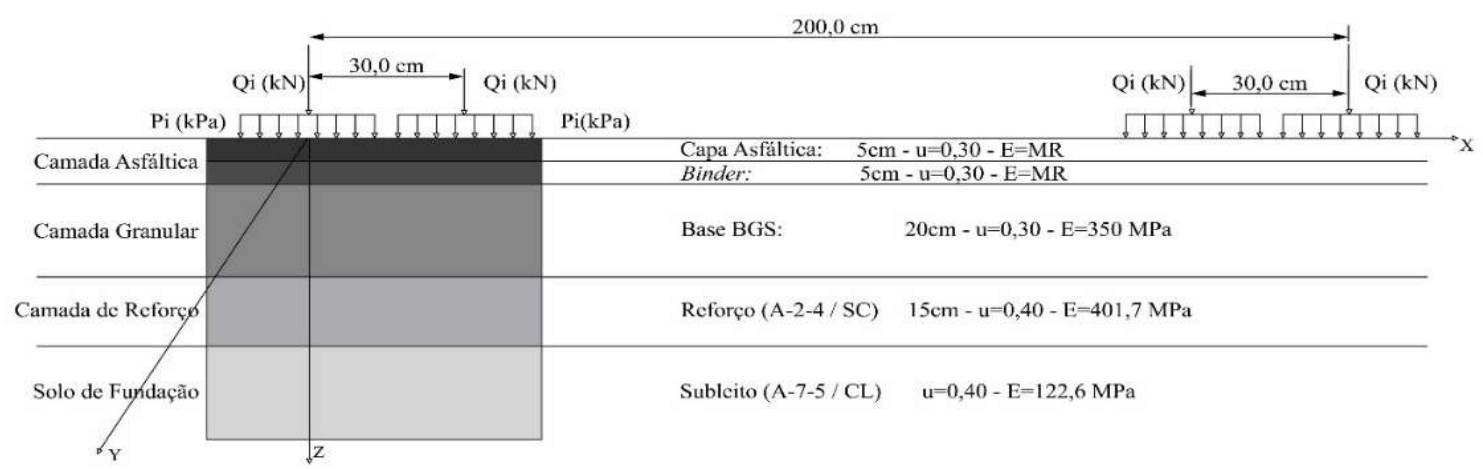

Figura 4: Pavimento flexível adotado para as análises estruturais. 


\section{Revista

Na Figura 5 são apresentadas as tensões horizontais $\left(\sigma_{\mathrm{h}}\right)$ que atuam na estrutura do pavimento flexível adotado, considerando as misturas asfálticas dosadas no teor de projeto de ligante asfáltico pelos métodos Marshall (Figura 5a) e Superpave (Figura 5b), para o carregamento de $80 \mathrm{kN}$ por eixo e pressão de enchimento do pneus de $563 \mathrm{kPa}$.

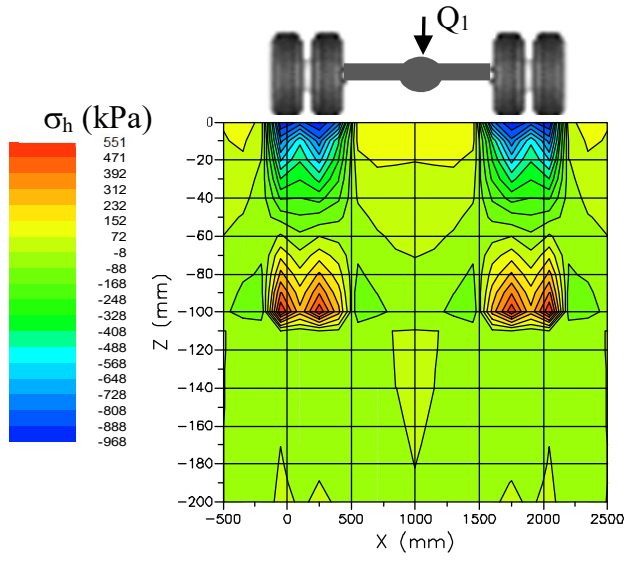

(a)

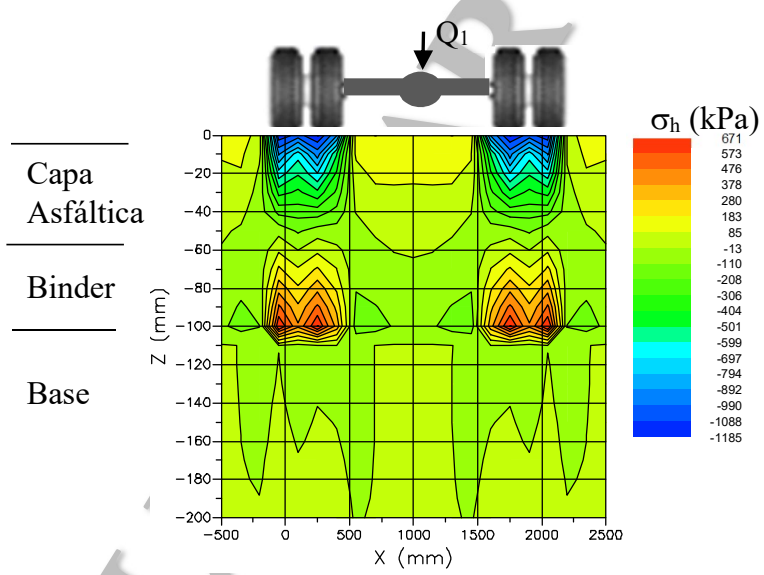

(b)

Figura 5: Tensões horizontais $\left(\sigma_{h}\right)$ na estrutura do pavimento flexível adotado.

Observa-se que as maiores tensões horizontais de tração $\left(\sigma_{h}\right)$ estão na fibra inferior da camada de binder, posição $(\mathrm{x})$ correspondente às maiores tensões horizontais de compressão $\left(\sigma_{\mathrm{h}}\right)$ na capa asfáltica, que estão concentradas sob os pontos de aplicação de carga (pontos sob os pneus). Assim, as análises estruturais do pavimento flexível adotado foram realizadas considerando as tensões e deslocamentos nestes pontos.

$\mathrm{Na}$ Tabela 4 são apresentadas as maiores tensões horizontais $(\sigma \mathrm{h})$ na fibra inferior das camadas asfálticas em função do método de dosagem, da variação do carregamento dos eixos e do teor de ligante asfáltico das misturas asfálticas analisadas.

Tabela 4: Tensões horizontais $\left(\sigma_{\mathrm{h}}\right)$ atuantes na fibra inferior das camadas asfálticas, na posição $\mathrm{x}=0 \mathrm{~mm}$, em função dos níveis de carregamento adotados, para as misturas asfálticas dosadas pelo método Marshall e Superpave.

\begin{tabular}{|c|c|c|c|c|c|c|c|c|}
\hline $\begin{array}{c}\text { Método de } \\
\text { dosagem }\end{array}$ & $\begin{array}{l}Q_{\text {eixo }} \\
(k N)\end{array}$ & $\begin{array}{l}P_{\text {pneus }} \\
(\mathbf{k P a})\end{array}$ & $\begin{array}{c}\text { Faixa } \\
\text { Granulométrica }\end{array}$ & $\begin{array}{l}T_{\text {Asf }} \\
(\%)\end{array}$ & $\begin{array}{c}\sigma_{\mathrm{h}} \\
(\mathbf{M P a})\end{array}$ & $\begin{array}{c}\text { Faixa } \\
\text { Granilométrica }\end{array}$ & $\begin{array}{l}T_{\text {Asf }} \\
(\%)\end{array}$ & $\begin{array}{c}\sigma_{\mathrm{h}} \\
(\mathrm{MPa})\end{array}$ \\
\hline \multirow{3}{*}{ Marshall } & 80 & 563 & \multirow{6}{*}{$\mathrm{C}$} & \multirow{3}{*}{4,7} & $-0,160$ & \multirow{6}{*}{ 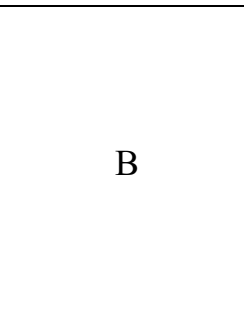 } & \multirow{3}{*}{4,2} & 0,628 \\
\hline & 98 & 633 & & & $-0,194$ & & & 0,726 \\
\hline & 118 & 703 & & & $-0,229$ & & & 0,827 \\
\hline \multirow{3}{*}{ Superpave } & 80 & 563 & & \multirow{3}{*}{4,6} & $-0,085$ & & \multirow{3}{*}{4,85} & 0,755 \\
\hline & 98 & 633 & & & $-0,107$ & & & 0,881 \\
\hline & 118 & 703 & & & $-0,132$ & & & 1,012 \\
\hline
\end{tabular}

Observação: ( - ) compressão e ( + ) tração, $\mathrm{T}_{\text {Asf: Teor de asfalto }}$ 


\section{Revista

Ao analisar as tensões horizontais $(\sigma \mathrm{h})$ que ocorrem na fibra inferior da capa asfáltica, obtidas pelo software me-PADS, verificou-se que estas são de compressão (sinal negativo), indicando que a linha neutra situa-se próxima à interface das duas camadas (capa asfáltica - faixa granulométrica $\mathrm{C}$ - e binder - faixa granulométrica B).

Para as tensões horizontais que atuam na fibra inferior da camada de binder, verificou-se que estas são de tração (sinal positivo). Analisando-se estas tensões horizontais, percebe-se que todos os carregamentos analisados apresentam valores inferiores aos encontrados para a resistência à tração por compressão diametral para os corpos de prova das misturas asfálticas dosadas pelos métodos utilizados em seus respectivos teores de projeto de ligante asfáltico, em que se observam resistência a tração de 1,33 MPa para as misturas asfálticas dosadas pelo método Marshall e 1,42 MPa para as misturas asfálticas dosadas pelo método Superpave.

A Figura 6 apresenta uma representação gráfica da variação das tensões horizontais ( $\sigma$ h) (apresentadas na Tabela 4) atuantes nas fibras inferiores das camadas asfálticas do pavimento flexível adotado, dosadas pelos métodos Marshall e Superpave, em função dos carregamentos adotados.

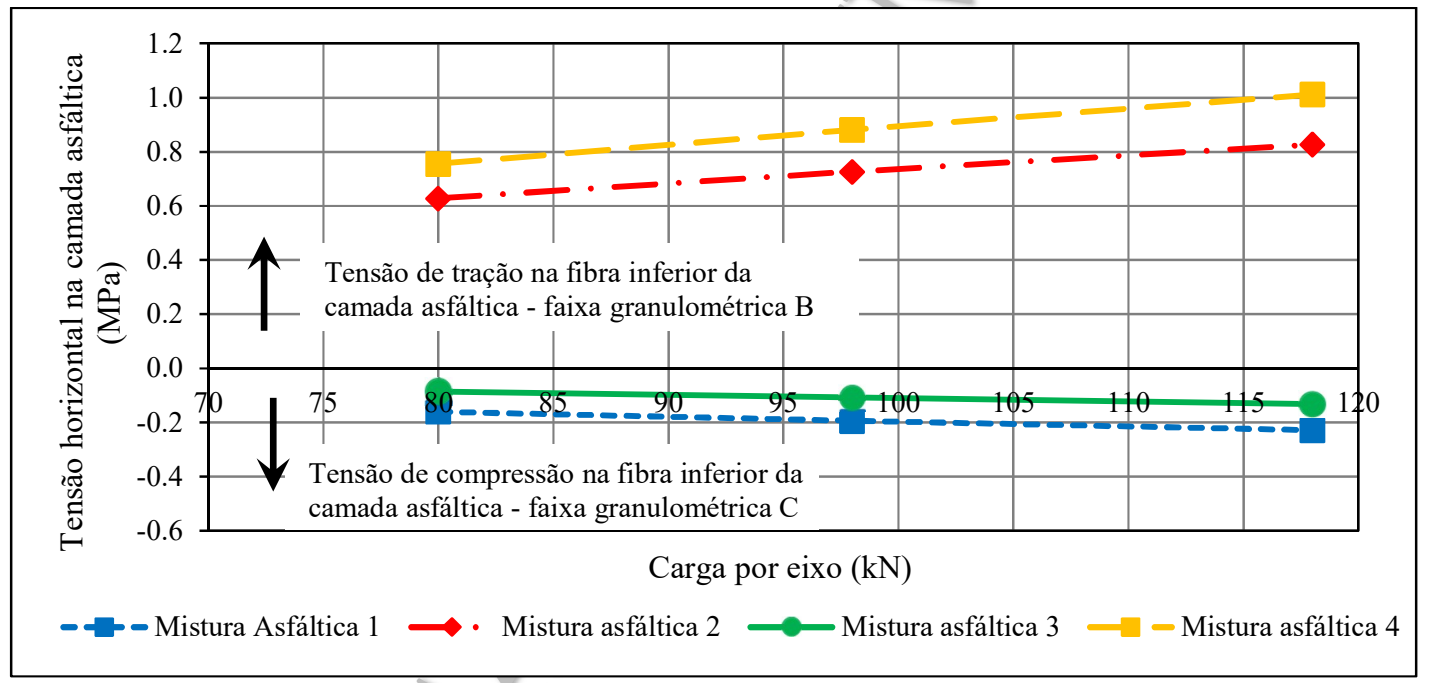

Figura 6: Tensões horizontais $\left(\sigma_{\mathrm{h}}\right)$ atuantes na fibra inferior das camadas asfálticas do pavimento flexível analisado em função dos níveis de carregamento adotados, na posição $\mathrm{x}=0 \mathrm{~mm}$.

Verifica-se, na Figura 6, que as tensões horizontais de tração atuantes na fibra inferior da camada do binder (faixa granulométrica B) do pavimento flexível adotado, cuja mistura asfáltica foi dosada pelo método Superpave são maiores (18\% em média) do que as obtidas para a mistura asfáltica dosada pelo método Marshall, para todos os níveis de carregamento analisados, evidenciando o efeito do processo de compactação por amassamento que promove o rearranjo das partículas dos agregados tornando a estrutura da mistura asfáltica mais rígida.

Já para as misturas asfálticas da faixa granulométrica $C$, as tensões horizontais de compressão obtidas para a mistura asfáltica dosada pelo método Marshall são maiores ( $45 \%$ em média) do que as obtidas para a mistura asfáltica dosada pelo método Superpave.

Esta diferença na resposta da estrutura dos pavimentos adotados está relacionada ao fato de que: por apresentarem módulo de resiliência inferiores às misturas asfálticas dosadas pelo método Superpave, as misturas asfálticas dosadas pelo método Marshall se mostram mais flexíveis do que as dosadas pelo método 
Superpave, de modo que as tensões concentradas no bordo inferior da capa asfáltica dissipam-se numa pequena área de influência em torno do ponto de concentração; enquanto as camadas correspondentes às misturas asfálticas dosadas pelo método Superpave, por apresentarem valores mais altos de módulo de resiliência, mostram-se mais rígidas, o que faz com que as tensões horizontais de tração se distribuam numa área maior. Isso se deve à diferença entre os processos de compactação empregados nos dois métodos estudados - Marshall (compactação por impacto) e Superpave (compactação por amassamento). Portanto, as camadas asfálticas modeladas a partir das misturas asfálticas obtidas com o método Marshall apresentam maior concentração de tensão nos pontos de aplicação de carga.

Na Figura 7 são apresentados os valores de deflexões verticais recuperáveis previstas na estrutura do pavimento flexível analisado, para o carregamento de $80 \mathrm{kN}$ por eixo e pressão de enchimento dos pneus de $563 \mathrm{kPa}$. A Figura 7a apresenta as deflexões verticais para as misturas asfálticas dosadas pelo método Marshall e a Figura $7 \mathrm{~b}$ as deflexões verticais para as misturas asfálticas dosadas pelo método Superpave.

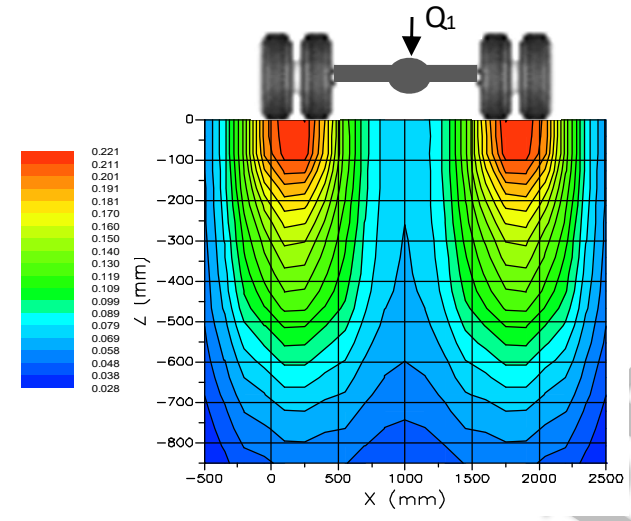

(a)

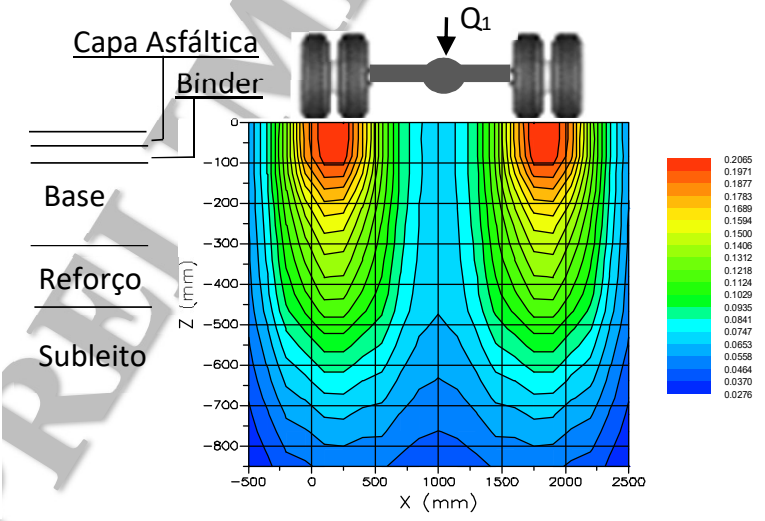

(b)

Figura 7: Deflexões verticais $(\delta \mathrm{z})$ na estrutura do pavimento flexível analisado para o carregamento por eixo de $80 \mathrm{kN}$ : (a) Mistura asfáltica dosada pelo método Marshall e (b) Mistura asfáltica dosada pelo método Superpave.

É possível verificar na Figura 7 que as maiores deflexões verticais recuperáveis ocorrem nas camadas asfálticas (capa asfáltica e binder) de maneira similar para ambos os métodos de dosagem analisados, sendo as deflexões apresentadas na camada asfáltica dosada pelo método Marshall, para o carregamento representado, superiores às da camada asfáltica dosada pelo método Superpave em cerca de $10 \%$, o que evidencia a maior flexibilidade da camada asfáltica dosada pelo método Marshall, como pode ser observado na Tabela 5.

As deflexões verticais recuperáveis máximas no topo da camada asfáltica do pavimento flexível adotado para cada um dos carregamentos analisados estão apresentadas na Tabela 5, em que as estruturas dos pavimentos estão representadas por camadas asfálticas dosadas pelos métodos Marshall e Superpave.

Para a avaliação dos valores de deflexões máximas apresentadas na Tabela 5, foram calculadas as deflexões admissíveis, segundo o procedimento PRO-011 (DNER, 1979), para um tráfego pesado $(\mathrm{N}=5 \times 107)$, de acordo com DNIT (2006). A deflexão admissível calculada para este nível de tráfego é de 45,18x0,01 mm e está representada pela linha tracejada apresentada na Figura 8. 


\section{Revista}

Tabela 5: Valores de deflexões verticais recuperáveis máximas no topo da camada asfáltica do pavimento flexível analisado.

\begin{tabular}{|c|c|c|c|c|c|}
\hline $\begin{array}{c}\text { Método de } \\
\text { dosagem }\end{array}$ & $\begin{array}{c}\text { Teor de } \\
\text { asfalto }(\%) \\
(\mathrm{FG}-\mathrm{C})\end{array}$ & $\begin{array}{c}\text { Teor de } \\
\text { asfalto }(\%) \\
(\mathrm{FG}-\mathrm{B})\end{array}$ & $\begin{array}{c}\text { Carga por eixo } \\
(\mathrm{kN})\end{array}$ & $\begin{array}{c}\text { Pressão de } \\
\text { enchimento } \\
(\mathrm{kPa})\end{array}$ & $\begin{array}{c}\text { Deflexão } \\
\text { recuperável } \\
(0,01 \mathrm{~mm})\end{array}$ \\
\hline \multirow{3}{*}{ Marshall } & \multirow{3}{*}{4,7} & \multirow{3}{*}{4,2} & 80 & 563 & 21,50 \\
\hline & & & 98 & 633 & 26,10 \\
\hline & & & 118 & 703 & 31,30 \\
\hline \multirow{3}{*}{ Superpave } & \multirow{3}{*}{4,6} & \multirow{3}{*}{4,85} & 80 & 563 & 19,70 \\
\hline & & & 98 & 633 & 24,00 \\
\hline & & & 118 & 703 & 28,80 \\
\hline
\end{tabular}

Observação: $\mathrm{FG}$ = faixa granulométrica

Para a avaliação dos valores de deflexões máximas apresentadas na Tabela 5, foram calculadas as deflexões admissíveis, segundo o procedimento PRO-011 (DNER, 1979), para um tráfego pesado $(\mathrm{N}=5 \times 107)$, de acordo com DNIT (2006). A deflexão admissível calculada para este nível de tráfego é de $45,18 \times 0,01 \mathrm{~mm}$ e está representada pela linha tracejada apresentada na Figura 8.

Observa-se, na Figura 8 , que as deflexões verticais $(\delta z)$ recuperáveis máximas para o pavimento flexível adotado, em que as misturas asfálticas foram dosadas pelos métodos Marshall e Superpave, apresentam valores de deflexões máximas inferiores aos valores das deflexões admissíveis determinadas para o nível de tráfego pesado, de acordo com DNIT (2006).

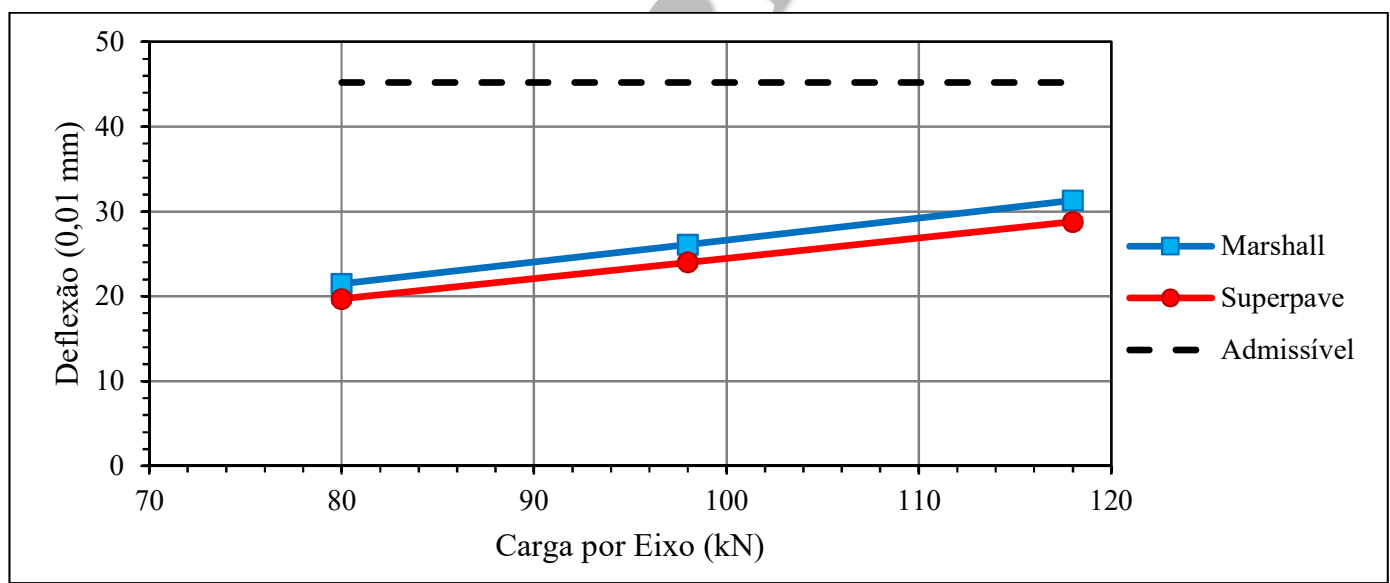

Figura 8: Deflexões verticais máximas na estrutura do pavimento flexível analisado em função dos carregamentos adotados para as misturas asfálticas dosadas pelos métodos Marshall e Superpave.

Analisando-se os valores de deflexões apresentados na Tabela 5 e representados na Figura 8, é possível observar que os valores das deflexões máximas medidas na superfície do pavimento flexível adotado, cujas misturas asfálticas foram dosadas pelo método Marshall são maiores (em média 8\%) do que os valores das deflexões máximas medidas na superfície do pavimento flexível adotado, cujas misturas asfálticas foram dosadas pelo método Superpave, o que evidencia o efeito das misturas asfálticas dosadas pelo método Superpave por serem mais rígidas (maior valor de módulo de resiliência - Tabela 2) quando comparadas às misturas asfálticas dosadas pelo método Marshall. 


\section{Revista PAVIMENTAÇÃO}

Conhecidos os níveis de tensões atuantes no pavimento flexível adotado, através das análises estruturais realizadas com o software me-PADS, para cada nível de carregamento adotado, determinou-se a vida de fadiga da estrutura do pavimento flexível adotado em função das misturas asfálticas dosadas pelos métodos Marshall e Superpave e das faixas granulométricas C e B da especificação de serviço ES-031 (DNIT, 2006), cujos valores estão apresentados na Tabela 6.

Tabela 6 - Valores de vida de fadiga das camadas asfálticas do pavimento flexível analisado em função dos carregamentos adotados no software me-PADS.

\begin{tabular}{|c|c|c|c|c|c|c|c|c|}
\hline $\begin{array}{l}\text { Mistura } \\
\text { asfáltica }\end{array}$ & $\begin{array}{c}\text { Método de } \\
\text { dosagem }\end{array}$ & $\mathrm{FG}^{(1)}$ & $\begin{array}{l}\mathrm{T}_{\text {Asf }} \\
(\%)\end{array}$ & $\begin{array}{l}\text { Qeixo }_{\text {en }} \\
(\mathrm{kN}) \\
\end{array}$ & $\begin{array}{c}\sigma_{\mathrm{h}}^{(2)} \\
(\mathrm{MPa})\end{array}$ & $\begin{array}{c}\sigma_{\mathrm{v}}^{(2)} \\
(\mathrm{MPa})\end{array}$ & $\begin{array}{c}\Delta \sigma^{(3)} \\
(\mathrm{MPa})\end{array}$ & $\begin{array}{l}\text { Vida de } \\
\text { Fadiga }\end{array}$ \\
\hline \multirow{3}{*}{1} & \multirow{6}{*}{ Marshall } & \multirow{3}{*}{$\mathrm{C}$} & \multirow{3}{*}{4,7} & 80 & $-0,160$ & $-0,411$ & 0,250 & $1,02 \times 10^{5}$ \\
\hline & & & & 98 & $-0,194$ & $-0,466$ & 0,272 & $8,42 \times 10^{4}$ \\
\hline & & & & 118 & $-0,229$ & $-0,522$ & 0,293 & $7,13 \times 10^{4}$ \\
\hline \multirow{3}{*}{2} & & \multirow{3}{*}{ B } & \multirow{3}{*}{4,2} & 80 & 0,628 & $-0,194$ & 0,822 & $4,36 \times 10^{3}$ \\
\hline & & & & 98 & 0,726 & $-0,231$ & 0,957 & $3,20 \times 10^{3}$ \\
\hline & & & & 118 & 0,827 & $-0,270$ & 1,097 & $2,43 \times 10^{3}$ \\
\hline \multirow{3}{*}{3} & \multirow{6}{*}{ Superpave } & \multirow{3}{*}{$\mathrm{C}$} & \multirow{3}{*}{4,6} & 80 & $-0,085$ & $-0,388$ & 0,303 & $1,45 \times 10^{5}$ \\
\hline & & & & 98 & $-0,107$ & $-0,441$ & 0,334 & $1,15 \times 10^{5}$ \\
\hline & & & & 118 & $-0,132$ & $-0,494$ & 0,362 & $9,45 \times 10$ \\
\hline \multirow{3}{*}{4} & & \multirow{3}{*}{ B } & \multirow{3}{*}{4,85} & 80 & 0,755 & $-0,165$ & 0,920 & $6,72 \times 10^{3}$ \\
\hline & & & & 98 & 0,881 & $-0,197$ & 1,078 & $4,06 \times 10^{3}$ \\
\hline & & & & 118 & 1,012 & $-0,231$ & 1,244 & $2,58 \times 10^{3}$ \\
\hline
\end{tabular}

${ }^{(1)} \mathrm{FG}$ : faixa granulométrica $\mathrm{T}_{\text {Asf: }}$ Teor de asfálto

As respostas estruturais determinadas evidenciam que, em função das cargas por eixo adotadas, as misturas asfálticas dosadas pelo método Superpave apresentam vidas de fadiga superiores às das misturas asfálticas dosadas pelo método Marshall (Figura 9).

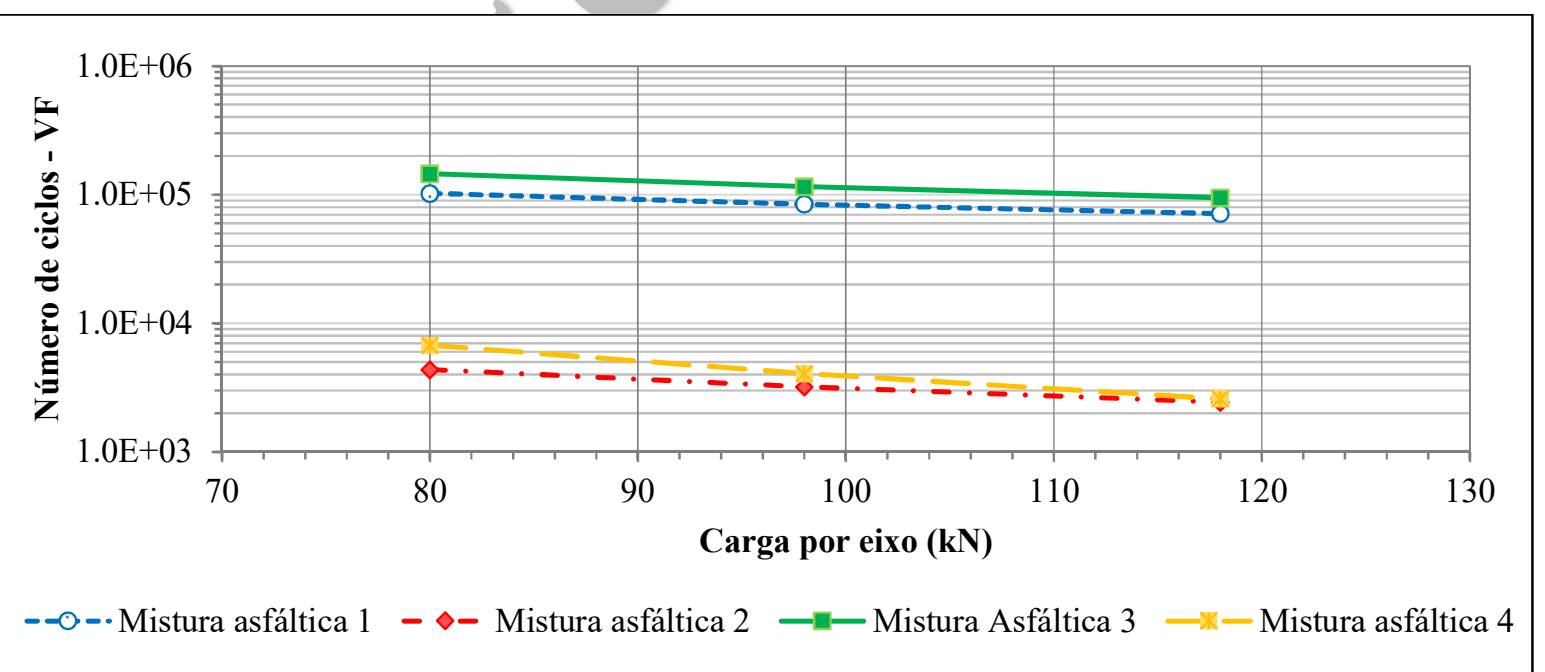

Figura 9: Valores de vida de fadiga das misturas asfálticas dosadas pelos métodos Marshall e Superpave para o pavimento flexível adotado. 
Analisando-se a Figura 9, evidencia-se que, para os níveis de carregamento adotados, os valores de vida de fadiga obtidos quando o pavimento flexível foi analisado considerando os parâmetros das misturas asfálticas dosadas pelo método Superpave (misturas asfálticas 3 e 4 - faixas granulométricas C e B, respectivamente) foram maiores do que quando o mesmo pavimento flexível foi analisado em função dos parâmetros das misturas asfálticas dosadas pelo método Marshall (misturas asfálticas 1 e 2 - faixas granulométricas $\mathrm{C}$ e $\mathrm{B}$, respectivamente). Estes resultados coadunam com os valores de módulo de resiliência (Tabela 2) e de curvas de fadiga obtidos para as misturas asfálticas analisadas (Figura 3), uma vez que as misturas asfálticas dosadas pelo método Superpave apresentaram-se mais rígidas, com gradiente de tensões mais distribuídos, cujos valores de Diferenças de Tensões ( $\Delta \sigma$ - Tabela 6 ) são da ordem de 1,0 $\mathrm{MPa}$ ou inferiores.

Da análise destes resultados, obtém-se que o método de dosagem apresenta influência predominante sobre a vida de fadiga (VF) e que a granulometria do agregado também afeta os valores de VF; sendo os maiores valores de VF obtidos para as misturas asfálticas com granulometrias densas dosadas pelo método Superpave - mistura asfáltica 3 .

\title{
5. CONCLUSÕES
}

Dos resultados obtidos nesta pesquisa conclui-se que as misturas asfálticas dosadas pelo método Superpave apresentam melhor desempenho a fadiga do que as misturas asfálticas dosadas pelo método Marshall, o que foi evidenciado pelos ensaios de fadiga por compressão diametral à tensão controlada e ratificado pelas análises estruturais no software me-PADS.

Além disso, pode se ressaltar que ao serem combinados os seguintes fatores: método de dosagem Superpave, adequados teores de projeto de ligante asfáltico e agregados de granulometria mais densa obtêm-se misturas asfálticas com melhores resultados de vida em fadiga, ou seja, maior durabilidade.

\begin{abstract}
Agradecimentos
Os autores agradecem as sugestões recebidas do professor doutor Taciano Oliveira da Silva da Universidade Federal de Viçosa, MG e do professor doutor Heraldo Nunes Pitanga da Universidade Federal de Juiz de Fora, que permitiram aprimorar o texto e eliminar diversas inconsistências. Este estudo foi parcialmente financiado pela Coordenação de Aperfeiçoamento de Pessoal de Nível Superior - Brasil (CAPES) - Código Financeiro 001.
\end{abstract}

\section{REFERENCIAS BIBLIOGRÁFICAS}

ALATAS, T.; YILMAZ, M.; KÖK, B.V.; KORAL, A.F., Comparison of permanent deformation and fatigue resistance of hot mix asphalts prepared with the same performance grade binders. Construction and Building Materials. v. 30, p. 66-72, 2012.

AL-QADI, I.L.; NASSAR, W.N., Fatigue shift factors to predict HMA performance. The International Journal of Pavement Engineering. v. 4, p. 69-75, 2003.

AASHTO. Designation: R 35-14, Standard Practice for Superpave Volumetric Design for Hot Mix Asphalt (HMA). AMERICAN ASSOCIATION OF STATE HIGHWAY AND TRANSPORTATION OFFICIALS. Washington, D.C. 2014.

ARABANI, M.; MIRABDOLAZIMI, S.M.. Experimental investigation of the fatigue behaviour of asphalt concrete mixtures containing waste iron powder. Materials Science and Engineering A. p. 3866-3870, 2011.

AMERICAN SOCIETY FOR TESTING AND MATERIALS - ASTM, 2011. D7369-11, Standard Test Method for Determining the Resilient Modulus of Bituminous Mixtures by Indirect Tension Test, ASTM International, West Conshohocken, PA, 2011.

AMERICAN SOCIETY FOR TESTING AND MATERIALS - ASTM, 2016. D6926-16, Standard Practice for Preparation of Asphalt Mixture Specimens Using Marshall Apparatus, ASTM International, West Conshohocken, PA, 2016. 
AMERICAN SOCIETY FOR TESTING AND MATERIALS - ASTM, 2017. D6931-17, Standard Test Method for Indirect Tensile (IDT) Strength of Asphalt Mixtures. ASTM International, West Conshohocken, PA, 2017.

BRAZ, D ; LOPES, R ; MOTTA, L. M. G., Research on fatigue cracking growth parameters in asphaltic mixtures using computed tomography. Nuclear Instruments \& Methods in Physics Research. Section B. Beam Interactions with Materials and Atoms, Brasil, v. 213, p. 498-502, 2004.

BOCK, A. L.; HARTMANN, D.; BUDNY, J.; SPECHT, L. P.; CERATTI, J. A. P., Estudo laboratorial sobre os efeitos de diferentes formas de adição de cal a concreto asfáltico. Teoria e Prática na Engenharia Civil. n. 14, p. 56-69. 2009.

CARMO, C.A.T.. Estudo do Comportamento Mecânico de Misturas Asfálticas à Quente com Diferentes Faixas Granulométricas e Métodos de Compactação com e sem Geogrelhas. Tese (Doutorado). Universidade Federal de Viçosa. 2019. 203p. https://www.locus.ufv.br/handle/123456789/27643

DEPARTAMENTO NACIONAL DE ESTRADA DE RODAGEM - DNER, 1979. PRO-011: Avaliação estrutural dos pavimentos flexíveis. Procedimento de ensaio. Departamento Nacional de Infraestrutura de Transportes (DNIT). Rio de Janeiro. 1979. 16 p.

DEPARTAMENTO NACIONAL DE INFRAESTRUTURA DE TRANSPORTES - DNIT, 2006. ES-031: Pavimentos Flexíveis - Concreto Asfáltico. Especificação de Serviço. Departamento Nacional de Infraestrutura de Transportes. Rio de Janeiro. 2006. 14 p.

DEPARTAMENTO NACIONAL DE INFRAESTRUTURA DE TRANSPORTES - DNIT, 2018. ME 135: Pavimentação asfáltica - Misturas asfálticas - Determinação do módulo de resiliência. Método de ensaio. Rio de Janeiro, 2018,13 p.

DEPARTAMENTO NACIONAL DE INFRAESTRUTURA DE TRANSPORTES - DNIT, 2018. ME 136: Pavimentação asfáltica - Misturas asfálticas - Determinação da resistência à tração por compressão diametral. Método de Ensaio. Rio de Janeiro, 2018, 9 p.

DEPARTAMENTO NACIONAL DE INFRAESTRUTURA DE TRANSPORTES - DNIT, 2018. ME 183: Pavimentação asfáltica - Ensaio de fadiga por compressão diametral à tensão controlada. Método de Ensaio. Rio de Janeiro, 2018,15 p.

FEDERAL HIGHWAY ADMINISTRATION - FHWA, 1995. AS-95-003. Background of SUPERPAVE asphalt mixture design and analysis. Federal Highway Administration. U.S. Department of Transportation. 1995. 160 p.

FRANCO, F.A.C.P., Um sistema para análise mecanística de pavimentos asfálticos. Tese (Doutorado). Universidade Federal do Rio de Janeiro, COPPE. 2000. 171 p.

FRITZEN, M.A. e MOTTA, L.M.G., Enfoque do desenvolvimento e validação da função de transferência para previsão do dano por fadiga de misturas asfálticas. $22^{\circ}$ Encontro de Asfalto. Rio de Janeiro. Brasil. 2016. $11 \mathrm{p}$.

HAN, D.; WEI, L.; ZHANG, J., Experimental Study on Performance of Asphalt Mixture Designed by Different Method. Procedia Engineering. v. 137. p. 407-414. 2016

JITSANGIAM, P.; CHINDAPRASIRT, P.; NIKRAZ, H., An evaluation of the suitability of SUPERPAVE and Marshall asphalt mix designs as they relate to Thailand's climatic conditions. Construction and Building Materials. v. 40, p. 961-970. 2013.

KARIMI, S.S.; GOULIAS, D.; SCHWARTZ, C.W., Evaluation of Superpave HMA mixture properties at the plant versus behind the paver: Statistical comparison of QC and QA data. Journal of Transportation Engineering, ASCE, v. 138, n. 7, p. 924932. July 2012.

LEITE, L.F.M.; MOTTA, L.M.G.; BERNUCCI, L.B. e SOARES, J.B., Mechanical behavior of asphalt rubber mixes prepared in laboratory. In: Asphalt Rubber. The Pavement Material of the 21st Century. Proceedings. Vilamoura, Portugal. 2000. Pp. 309-318.

LOUREIRO, T.G.; SOARES, J.B. e MOTTA, L.M.G., Estudo sobre o dano progressivo em misturas asfálticas no ensaio de fadiga à compressão diametral. XVII Congresso de Ensino e Pesquisa em Transportes, ANPET, Rio de Janeiro. 2003.12 p.

MASHAAN, N.S.; KARIM, M.R.; AZIZ, M.A.; IBRAHIM, M.R.; KATMAN, H.Y.; KOTING, S., Evaluation of fatigue life of CRM-reinforced SMA and its relationship to dynamic stiffness. Hindawi Publishing Corporation. The Scientific World Journal. v. 2014, 2014. 11 p.

MEDINA, J.; MOTTA, L.M.G., Mecânica dos Pavimentos. 3a ed., Editora Interciência, Rio de Janeiro - RJ, 2015,620 p.

MELO, J. V. S.; TRICHÊS, G., Evaluation of rheological behavior and performance to permanent deformation of nanomodified asphalt mixtures with carbon nanotubes. Canadian Journal of Civil Engineeering. v. 43. p. 472-479, 2016.

MOGHADDAM, T. B.; KARIM, M. R.; ABDELAZIZ, M., A review on fatigue and rutting performance of asphalt mixes. Scientific Research and Essays. v. 6, n. 4, p. 670-682, 2011.

NASCIMENTO, Luis Alberto Herrmann Do ; LEITE, Leni F Mathias ; MARQUES, Geraldo Luciano de Oliveira ; MOTTA, L. M.G., Uso de tomografia computadorizada e de imagens digitais para o estudo de misturas asfálticas. Revista Estradas (Porto Alegre), v. 11, p. 58-65, 2007. 


\section{Revista PAVIMENTAÇÃO}

PÉREZ-JIMÉNEZ, F.; MARTÍNEZ, A.H.; MIRÓ, R.; HERNÁNDEZ-BARRERA, D.; ARAYA-ZAMORANO, L., Effect of compaction temperature and procedure on the design of asphalt mixtures using Marshall and gyratory compactors. Construction and Building Materials. n. 65, 2014, p. 264-269.

PINHEIRO, J.H.M., SOARES, J.B. e LEITE, L.F.M., Caracterização de misturas asfálticas com borracha produzidas pelo processo úmido e seco. Congresso de Pesquisa e Ensino em Transportes, XVII ANPET. Anais. Vol 1. Rio de Janeiro. 2003. p 116-129.

PINTO, S., Estudo do comportamento à fadiga de misturas betuminosas a aplicações na avaliação estrutural de pavimentos, Dissertação de Tese de Doutorado - COPPE/UFRJ, 1991.

STRATEGIC HIGHWAY RESEARCH PROGRAM - SHRP, 1994., A-407, The Superpave Mix Design Manual for New Construction and Overlays. STRATEGIC HIGHWAY RESEARCH PROGRAM. Washington, DC. National Research Council. 1994. $172 \mathrm{p}$.

VASCONCELOS, K.L. Comportamento mecânico de misturas asfálticas à quente dosadas pelas metodologias Marshall e Superpave com diferentes granulometrias. Dissertação (Mestrado em Engenharia de Transportes). Universidade Federal do Ceará, Fortaleza, 2004. 149 f.

WU, B.; LIU, L.; SUN L. Analysis of parameters affecting asphalt mixture performance and new perspectives on the design parameters. Construction and Building Materials. v. 174 p. 625-632. 2018. 